RU Герменевтическая модель художественного перевода интертекстуальных знаков с русского языка на английский

Рябко Е. И.

\begin{abstract}
Аннотация. Данная статья посвящена исследованию категории интертекстуальности в рамках герменевтической модели переводческой деятельности. Цель исследования - представить практическую модель анализа-сопоставления текста оригинала художественного произведения и его переводов с русского языка на английский, направленную на понимание мотивации принятия переводческих решений, оценивание результатов и смысловых расхождений. Научная новизна состоит в разработке комплексной модели анализа, органично сочетающей переводческую методологию и технологию. В результате доказано, что сопоставительные смысловые отношения между текстом-источником интертекстуальных заимствований, исходным художественным и переводными текстами обладают гомоморфным характером, смысловые вариации возникают ввиду индивидуальных особенностей восприятия, понимания, интерпретации, выбора способов перевыражения усвоенного смыслового содержания.
\end{abstract}

\title{
EN Hermeneutic Model of Literary Translation of Intertextual Signs from Russian into English
}

\author{
Ryabko Y. I.
}

\begin{abstract}
The article is devoted to the study of the intertextuality category within the framework of the hermeneutic model of translation activity. The research aims to present a practical model for analysing and comparing the original text of a literary work and its translations from Russian into English, aimed at understanding motivation for making translation decisions, assessing results and semantic discrepancies. Scientific novelty of the research lies in developing a comprehensive model for analysis that naturally combines translation methodology and technology. As a result, it is proved that comparative semantic relations between a text which serves as a source of intertextual borrowings, an original literary text and its translations are of homomorphic nature, semantic variations appear due to individual features of perception, understanding, interpretation, and the choice of ways to reproduce the acquired semantic content.
\end{abstract}

\section{Введение}

Художественный перевод является востребованным и перспективным направлением, поскольку, какими бы быстрыми темпами ни развивался машинный перевод в современном обществе и как бы ни повышалось его качество, только сознание человека способно прочувствовать, вообразить, проникнуть в удивительный мир художественного произведения, понять и интерпретировать палитру его смысловых оттенков и найти языковые аналоги, воплощая результат литературного творчества на языке иной культуры.

Актуальность исследования обусловлена потребностью поиска новых способов перевода и оценки качества продукта художественной переводческой деятельности. Исследование является актуальным для современного общества, в котором художественная литература занимает важное место, удовлетворяя интеллектуальные и духовные потребности целевой аудитории; перевод художественного произведения содействует развитию языковых, аналитических, творческих способностей, воспитанию межкультурного взаимопонимания, способности признавать и уважать право быть другим, развитию умения вести межкультурный диалог, что, несомненно, необходимо нашему современному миру.

Реализация поставленной цели предполагает последовательное решение следующих задач: во-первых, обоснование теоретической базы исследования и определение содержания ключевых понятий (интертекстуальность, интертекстуальный знак, интертекстуальная компетенция, художественный перевод, герменевтика); во-вторых, разработка двухэтапной сопоставительной герменевтической модели перевода интертекстуальных 
знаков, представляющей собой технологический механизм воспроизведения полноценных объемов смыслов в процессе художественного перевода с русского языка на английский; в-третьих, апробация разработанной модели на выбранном материале (канонический текст романа М. А. Булгакова «Мастер и Маргарита» и его английские переводы).

В работе использован комплекс таких обще- и частнонаучных методов исследования, как: сравнительный и сопоставительный, методы синтеза и анализа, метод герменевтического анализа.

Теоретической базой исследования являются труды отечественных и зарубежных ученых в сфере филологической герменевтики, теории интертекстуальности и теории художественного перевода Г. Г. Гадамера, Ю. Кристевой, Н. Пьеге-Гро, Г. В. Денисовой, Л. К. Латышева, Н. К. Гарбовского и др.

Практическая значимость исследования заключается в том, что представленный материал может быть использован в вузах гуманитарного направления в ходе разработки теоретических и практических курсов и спецкурсов по интерпретации художественного текста, литературоведческому анализу и переводу. Полученные данные также могут найти применение в процессе учебно-методической деятельности при создании учебных пособий и рекомендаций для студентов, изучающих художественную литературу и художественный перевод, практикующих переводчиков.

\section{Проблема понимания, интерпретации, перевода художественного текста}

Одним из механизмов формирования смыслового содержания образов и сюжетных линий художественного произведения, который необходимо понять переводчику, адекватно интерпретировать и передать лингвистическими средствами принимающей культуры, выступает феномен интертекстуальности. Понятие «интертекстуальность» обозначает свойство, которое выражается в существовании между текстами отношений и связей, благодаря которым данные тексты разнообразными способами ссылаются друг на друга, вступают в диалог [8, с. 167]. Интертекстуальность художественного текста, в свою очередь, определяется как присутствие смыслового содержания одного текста в другом, их переплетение и взаимодействие. В результате такого соприкосновения формируется текстовая многоплановость, происходит расширение границ произведения искусства, углубление и развитие его содержательного пространства, увеличивается художественная ценность [9, с. 112].

Разнообразие средств выражения интертекстуальных связей позволяет объединить их под зонтичным термином «интертекстуальный знак». В рамках изучения данной темы рассматриваются такие интертекстуальные знаки, как заголовки, эпиграфы, цитата, аллюзия, реминисценция, стилизация, пародия, референция, плагиат, жанровое варьирование, сюжетное варьирование, прецедентные феномены, говорящие имена, дописывание чужого текста и др., генерирующие смыслы художественного произведения. Интертекстуальные отношения возможно выявить не только между текстами, но и между дискурсами и жанрами, а также обратившись к другой семиотической системе. Речь идет о других видах и направлениях искусства - живописи, графике, фотоискусстве, скульптуре, архитектуре, музыке, балете, кинематографе и др. [7; 9].

Для успешной идентификации и интерпретации такого полифонического диалога получатель текста (читатель, исследователь, переводчик) должен обладать солидным читательским опытом и определенным объемом знаний, иными словами, быть «интертекстуально компетентным» [7, с. 147-149]. Отметим, что формирование и развитие интертекстуальной компетенции происходит естественным образом, на протяжении жизни человека в ходе обучения, общения, приобретения опыта, благодаря установлению межпредметных отношений и связей, самообразованию.

Художественный перевод - это вид межъязыкового и межкультурного посредничества [4, с. 242-243]. Традиционно отношения между текстом оригинала и перевода описываются в категориях адекватности и эквивалентности, а поиск и анализ переводческих решений осуществляются в рамках трансформационной теории. Однако продукт художественного перевода (текст перевода) является скорее подобием, проекцией, одним из вероятных аналогов оригинала литературного произведения, нежели его иноязычным эквивалентом. Перевод преследует свою определенную цель: он воспроизводит эстетическую ценность исходного текста, стремится достичь конгениальности с автором оригинала. Это позволяет определить и оценить переводческую деятельность через понятия симметрии и асимметрии, изоморфизма и гомоморфизма, а также выйти за рамки теории трансформаций [4]. Трансформационная модель перевода относится к так называемым лингвистическим моделям перевода. Термин «трансформация» пришел в теорию перевода из генеративной лингвистики, где трансформация была представлена как процесс преобразования основных ядерных структур с целью порождения вторичных. Таким образом, теория трансформаций является представлением лишь одного из аспектов такой сложной деятельности, как перевод [Там же]. Перевод как сложная интерпретирующая деятельность представляет собой не только взаимодействие систем языков, но и взаимодействие систем смыслов. Соответственно, изучение художественного перевода не может быть полным, если оставить в стороне культурологические, социологические, антропологические, психологические и иные аспекты этой деятельности. Герменевтическое направление позволяет вывести исследование за пределы одной лингвистики, подход становится междисциплинарным. Герменевтика позволяет включить в анализ экстралингвистические факторы, личность переводчика. В рамках данного подхода перевод не сводится к набору каких-то определенных верных моделей, поскольку не представляется возможным представить искусство художественного перевода как совокупность технических приемов по преобразованию текста на одном языке в текст на другом языке [12]. 


\section{Двухэтапная сопоставительная герменевтическая модель перевода интертекстуальных знаков}

Вышеописанные теоретические установки, по мнению автора статьи, должны быть заложены в основу методологии анализа исходного художественного текста и переводных текстов, разработку эффективной методологии исследования способов передачи смыслового содержания в переводах на разные языки. Разработанная методология направлена также на поиск языковых средств выражения выявленных смыслов в языке перевода, соответственно, может быть интересна и практикующим переводчикам. Методология разработана в рамках сопоставительного герменевтического подхода и состоит из двух этапов:

1) формирование предпонимания сюжетного содержания текста оригинала литературного произведения и его текстов перевода;

2) этап переводческой деятельности, представленный тремя подэтапами: процесс понимания, процесс интерпретации, анализ переводческих трансформаций.

Объясним каждый из них.

Задача первого этапа заключается в создании «стартового», предварительного, базового понимания содержания анализируемых текстов. На этой ступени анализа, помимо внимательного ознакомления с текстом (отрывком текста) оригинала и его переводами, студентам предлагается изучить экстралингвистические данные (биография автора, яркие исторические и культурные события эпохи создания произведения, потенциально оказавшие влияние на сюжет, история публикаций объекта исследования (при условии наличия особенностей), данные о времени появления текстов перевода, переводчиках). Первый этап предусматривает также элементы литературоведческого анализа, нацеленного на определение отличительных особенностей воображаемого мира и литературной ценности произведения. Сформированное предпонимание дает стимул, толчок, задает вектор развитию исследовательской мысли, углубляется и корректируется в ходе второго этапа анализа.

Этап переводческой деятельности предполагает три подэтапа анализа: понимание и интерпретацию смыслового содержания текста-источника (имеется в виду источник, из которого заимствованы интертекстуальные знаки), оригинала литературного произведения и аналогов-переводов на иностранный язык; определение технологии перевода, выбор соответствующих межъязыковых и межкультурных переводческих приемов (переводческих трансформаций).

Универсальная познавательная операция понимания упорядочивает и организовывает содержание знания, сформированного на предыдущем этапе, выявляет новые свойства и особенности объекта исследования, сопоставляя их с уже воспринятой сознанием информацией. Понимание, таким образом, определяем как процесс восприятия и осознания смыслов исследуемых текстов. Понимание является вспомогательным видом деятельности, который естественным образом переходит в интерпретацию исследуемых объемов смыслов.

Интерпретация представляет собой творческую деятельность. Интерпретация - процесс раскрытия, углубления, толкования объемов выделенных смыслов. Сопоставление образов и сюжетных линий (структурных компонентов художественного произведения) в авторском и переводческом текстах базируется на гипотезе о том, что они содержат аналогичные объемы смыслов изоморфного или/и гомоморфного характера. Понятия «изоморфизм» и «гомоморфизм» пришли в лингвистику из математики и логики [4]. В рамках разрабатываемой модели применяются для установления отношений между системами текстовых смыслов: если образ или сюжетная линия в тексте перевода всецело соответствует своему прообразу или прообразной сюжетной линии в тексте оригинала, следует вывод о наличии между ними отношений изоморфизма-тождества. В случае если эти структурные компоненты финального текста содержат не весь объем смысла, имеющийся в оригинальных, либо привносят дополнительные смысловые оттенки, между данными текстами устанавливаются отношения гомоморфизма-уподобления, иными словами, отношения языковой и культурной асимметрии [10].

Как показывают практика и анализ переводческой деятельности, процесс воспроизведения смыслов в интерпретирующем тексте сопровождается либо смысловыми потерями, либо наполнением текста перевода дополнительными смыслами, что объясняется естественной асимметрией языков и культур.

Под переводческими трансформациями в данном подходе понимается набор приемов, используемых в переводе с одного языка на другой. Переводческие трансформации - технологичный инструмент перевода. С точки зрения выбранного методологического подхода (филологической герменевтики) интерес представляет классификация приемов известного исследователя, переводчика Л. К. Латышева [7]. В данной типологии переводческие преобразования рассматриваются не только как приемы изменения языковых знаков на различных уровнях языковой системы [5], но и как приемы реконструирования смысла.

Подчеркнем, что ступени второго этапа анализа тесно переплетены в сознании интерпретатора, взаимообусловлены и взаимосвязаны, протекают вкупе друг с другом [10].

\section{Применение герменевтической модели художественного перевода интертекстуальных знаков}

В статье текстовым материалом апробации герменевтической модели художественного перевода интертекстуальных знаков выбраны Библия, оригинал романа М. А. Булгакова «Мастер и Маргарита», пять текстовпереводов произведения на английский язык, авторами которых являются М. Гинзбург (1967), М. Гленни (1967), Д. Бургин и К. Т. О’Коннор (1995), Р. Пивер и Л. Волохонская (1997) и Х. Эплин (2008). Анализ 
нижеприведенного примера демонстрирует способ выявления сопоставительных отношений между исходными библейскими, авторскими и переводческими смыслами интертекстуальных включений с применением разрабатываемой методологии.

На первом этапе, этапе предпонимания, устанавливаем, что отличительной чертой всемирно известного романа «Мастер и Маргарита» писателя-драматурга М. А. Булгакова является его философско-историческая тематика. Произведению свойственны разнообразные интертекстуальные связи с творениями отечественной и мировой литературы, истории и культуры, а также фактами жизни самого писателя, его родных и знакомых. В произведении обнаруживается немалое число интертекстуальных знаков-отсылок к библейским персонажам и сюжетным линиям. Вне зависимости от отношения к религии каждого из нас невозможно оспорить тот факт, что Библия является неиссякаемым источником литературных образов, сюжетов и жанров. Священное Писание - начало начал мировой литературы и великий памятник искусства. На её канонах развивались как русская литература и культура, так и литература и культура других стран. Литературнохудожественный фон романа, таким образом, универсален, симметричен для представителей практически любого национально-культурного сообщества. При этом не существует одинаковых ментальных репрезентаций и ментальных образов сознания, языковое сознание всегда уникально и индивидуально.

Переходя на следующий этап анализа - этап переводческой деятельности, - рассмотрим пример, являющийся лишь небольшой зарисовкой образа римского прокуратора Понтия Пилата, который, будучи убежденным в невиновности Иешуа, намерен утвердить смертный приговор и отправить бродячего философа на страшную казнь. Принимая решение, прокуратор наблюдает непонятное видение: «Мысли понеслись короткие, бессвязные и необыкновенные: “Погиб!”, потом: “Погибли!..” И какая-то совсем нелепая среди них о какомто долженствующем непременно быть - и с кем?! - бессмертии, причем бессмертие почему-то вызывало нестерпимую тоску» [1, с. 28].

Из цитаты следует, персонаж подсознательно чувствует, что, вынося этот вердикт, он обрекает свою душу на вечную гибель. Более того, его малодушное решение обрекает на гибель души всего человечества, которое потеряло навеки свой путь к Богу.

Англоговорящие переводчики понимают, интерпретируют и воспроизводят в переводе смысловое содержание эпизода по-своему:

1) M. Ginsburg: Short, incoherent and extraordinary thoughts rushed through Pilate's mind. “Lost!” Then, “We are lost!" And then an altogether absurd idea among the others, about some sort of immortality, and for some reason the thought of immortality gave him intolerable anguish [12].

2) M. Glenny: Strange, rapid, disconnected thoughts passed through his mind. 'Dead!' Then: 'They have killed him!...' And an absurd notion about immortality, the thought of which aroused a sense of unbearable grief [13, p. 28].

3) D. Burgin, K. T. O’Connor: Brief, strange, disconnected thoughts spread through his brain, "He is lost!" - then, "We are lost!" And included among them was a totally absurd notion about some sort of immortality, and for some reason this immortality evoked a sense of unbearable anguish [10, p. 21].

4) R. Pevear, L. Volokhonsky: Thoughts raced, short, incoherent and extraordinary: 'I'm lost!..' then: 'We're lost!..' And among them a totally absurd one, about some immortality, which immortality for some reason provoked unendurable anguish $[14$, p. 34-35].

5) H. Aplin: His thoughts raced, brief, incoherent and extraordinary. "He's done for!" then: "We're done for!" And among them was one utterly absurd one about some sort of immortality, and immortality for some reason provoked unbearable anguish [11].

Анализ представленных выше вариантов перевода данного эпизода указывает на то, что все переводчики используют вариантные аналоги-соответствия, по-разному декодируя авторские смыслы.

Лексическая единица “lost”, выбранная Миррой Гинзбург в качестве ключевого соответствия, невероятно ёмкая в смысловом отношении, имеет следующие словарные дефиниции: 1) to be impossible to find; 2) to turn to annihilation and dematerialization; 3) to lose one's possession of something really desirable or precious; 4) to fail to withhold or retail [15]. Вариант перевода предполагает, что Пилат совершает страшный грех, лишается способности сохранить чистоту души, утрачивает свой путь в жизни, уничтожает свою бесценную душу. При этом римский наместник принимает решение осознанно и самостоятельно, без внешнего давления. Таким образом, вина и ответственность только его.

Майкл Гленни теряет в переводе лексический повтор словоформ. В авторском оригинале Понтий Пилат, повторяя «Погиб!», «Погибли!..», навеки связывает свою судьбу с судьбой Иешуа, что важно в дальнейшем развитии сюжета произведения. В оригинальном фрагменте Пилат чувствует, что обречен разделить печальную судьбу заключенного. В переводе данный смысловой оттенок отсутствует, чему также способствует выбор местоимения “they”, которое смещает акценты. Соответствие “dead”, выбранное переводчиком, является слишком однозначным. Оно передает лишь идею физической смерти (dead - no longer alive_[Ibidem]), в то время как в оригинале речь идет о более возвышенном смысле, бессмертии души. Аналог “Тhey have killed him!” полностью лишает прокуратора ответственности за решение подтвердить виновность Иешуа.

Диана Бургин и Кэтрин Т. О’Коннор сохраняют лексический повтор и передают смысловой оттенок высокой доли ответственности Понтия Пилата. В первом предложении переводчики вводят личное местоимение “Не”. В этом варианте нет двусмысленности оригинала, возникающей благодаря форме глагола «Погиб!», которая может подразумевать как личное местоимение первого, так и третьего лица (Я погиб / Он погиб?). Прокуратора прежде всего волнует судьба Иешуа (“Не is lost!”), которую он связывает со своей (“We are lost!”). 
Переводчики Ричард Пивер и Лариса Волохонская так же, как и М. Гинзбург, Диана Бургин и Кэтрин T. О’Коннор, останавливают свой выбор на соответствии “lost”. Однако в первом случае они вводят личное местоимение "I".

Хью Эплин применяет в переводе приемы синтаксической трансформации и метафоризации. Находим в словаре следующие дефиниции образного словосочетания “to be done for": 1) to be destined to fail, die or be destroyed; 2) to be ill-fated, find yourself in a situation so hopeless that it is unthinkable to get out of it; 3) to be unable to retain something, be lost, dead [Ibidem]. У Х. Эплина Понтий Пилат попадает в чрезвычайно трудную, безвыходную, безнадежную ситуацию. Он вынужден принять решение, противоречащее его убеждениям и совести. Прокуратор не может избежать этого. В интерпретации переводчика Пилат обречен, ему уготована судьба совершить роковую ошибку, иными словами, вина не его. Этот поступок обусловлен некими высшими силами или факторами, которым он неспособен противодействовать.

В результате анализа фрагмента приходим к следующим выводам относительно смыслового содержания рассмотренных вариантов.

В книгах Священного Писания Понтий Пилат описывается как жестокий наместник, хитрый политик, презиравший и ненавидевший народ Иудеи и его веру, и, прежде всего, он - тот человек, который осудил Иисуса Христа и отправил на распятие.

М. А. Булгакова привлекает внутренний, духовный мир персонажа. Писатель уделяет много внимания внутриличностному конфликту, борьбе Понтия Пилата с самим собой, пытается понять мотивы его поступка, сомнения, чувства и переживания. Писатель ставит своего героя перед трудным нравственным выбором: поступить честно, по совести, правильно с моральной точки зрения и сохранить жизнь невиновного человека, но при этом лишиться своего привилегированного положения, подвергнуть собственную жизнь опасности либо сохранить собственный статус, привилегии и жизнь, убив бродячего философа. Такое ответственное решение литературный герой должен принять сам, осознавая свою ответственность и наказание.

В английских переводах данного фрагмента Пилат несет не одинаковую меру ответственности за свой поступок. В интерпретациях переводчиков М. Гинзбург, Д. Бургин и К. Т. О’Коннор, Р. Пивера и Л. Волохонской римский прокуратор осознает сущность совершаемых им действий, подтверждает приговор и отправляет Иешуа на страшную казнь осмысленно, поэтому степень его виновности велика. При этом переводчики поразному расставляют акценты во внутреннем монологе прокуратора. М. Гленни «перекладывает» ответственность, обвиняя в смерти Иешуа других (возможно, имея в виду представителей Синедриона, которые наняли Иуду). Его Понтий Пилат не испытывает духовной связи с обвиняемым. У Х. Эплина Пилат разрешает казнь под давлением внешних факторов. Это снижает меру его ответственности за принятое решение.

\section{Заключение}

Проведенное исследование позволяет сделать следующие выводы: художественный перевод является непростой, но чрезвычайно интересной задачей, в ходе решения которой раскрывается профессиональный и творческий потенциал участников переводческой деятельности. Исследование доказало перспективность применения герменевтического подхода в его филологической трактовке как теории понимания смыслов интертекстуальных знаков и их интерпретации при сопоставлении текста-источника, оригинального текста и переводов. Предлагаемая методология позволяет за счет соотнесения симметрии и асимметрии смыслов интертекстуальных знаков, созданных в рамках разных культур, осуществить выход в сложные смыслы (социоисторические, культурные, эстетические и др.).

Разработанная герменевтическая модель анализа художественного перевода интертекстуальных знаков является попыткой упорядочить процесс анализа переводческой деятельности, охватить все аспекты художественного переводческого процесса, углубить представление о процессах понимания и интерпретации художественного текста, возможностях перевода с одного языка на другой. Анализ примеров доказывает, что интертекстуальные знаки переводного текста воплощают переводческую концепцию, актуализируя проекцию оригинала на сознание переводчика.

Перспективой данного исследования является развитие герменевтической концепции анализа интертекстуальных включений, направленной на преодоление атомарности лингвистического подхода и объяснение противоречивости переводческой реальности.

\section{Источники | References}

1. Булгаков М. А. Мастер и Маргарита. Симферополь: Таврия, 2018. 404 с.

2. Гадамер Х. Г. Истина и метод: основы философской герменевтики. М.: Прогресс, 1998. 704 с.

3. Гарбовский Н. К. Теория перевода. М.: Юрайт, 2020. 387 с.

4. Денисова Г. В. В мире интертекста: язык, память, перевод. М.: Азбуковник, 2003. 298 с.

5. Комиссаров В. Н. Лингвистика перевода. М.: Либроком, 2016. 176 с.

6. Кристева Ю. Избранные труды: разрушение поэтики. М.: РОССПЭН, 2004. 656 с.

7. Латышев Л. К. Технология перевода. М.: Юрайт, 2020. 263 с.

8. Пьеге-Гро Н. Введение в теорию интертекстуальности. М.: ЛКИ, 2008. 240 с. 
9. Рябко Е. И. Библейские интертекстуальные включения в аспекте филологической герменевтики (на материале романа М. А. Булгакова «Мастер и Маргарита» и его переводов): дисс. ... к. филол. н. Хабаровск, 2019. 208 c.

10. Bulgakov M. The Master and Margarita / translated from Russian by D. Burgin, K. Tiernan O’Connor. L.: Picador, 1997. $368 \mathrm{p}$.

11. Bulgakov M. The Master and Margarita / translated from Russian by H. Aplin. L.: Alma/Oneworld, 2008. 432 p.

12. Bulgakov M. The Master and Margarita / translated from Russian by M. Ginsburg. N. Y.: Grove Press, 1967.402 p.

13. Bulgakov M. The Master and Margarita / translated from Russian by M. Glenny. L.: Vintage, 2004. 445 p.

14. Bulgakov M. The Master and Margarita / translated from Russian by R. Pevear, L. Volokhonsky. L.: Penguin Classics, 2004. $564 \mathrm{p}$.

15. https://en.oxforddictionaries.com (дата обращения: 27.12.2020).

\section{Информация об авторах | Author information}

RU Рябко Елена Игоревна ${ }^{1}$, к. филол. н.

${ }^{1}$ Тихоокеанский государственный университет, г. Хабаровск

EN Ryabko Yelena Igorevna ${ }^{1}, \mathrm{PhD}$

${ }^{1}$ Pacific State University, Khabarovsk

${ }^{1}$ elena-r.kha@mail.ru

\section{Информация о статье | About this article}

Дата поступления рукописи (received): 30.03.2021; опубликовано (published): 31.05.2021.

Ключевые слова (keywords): интертекстуальный знак; интертекстуальная компетенция; филологическая герменевтика; художественный перевод; герменевтическая модель художественного перевода; intertextual sign; intertextual competence; philological hermeneutics; literary translation; hermeneutic model of literary translation. 